\title{
Burden of smoking in Asia-Pacific countries
}

\author{
Vivian W. Y. Lee', Anna Li', Joyce T. S. Li ${ }^{1}$
}

\section{ABSTRACT}

INTRODUCTION Smoking is a modifiable risk factor for many diseases. The public should recognize the impact of smoking on their health and their wealth. The current study aimed to evaluate the cost burden of smoking to target Asia-Pacific countries.

METHODS The current study estimated the annual spending and lifetime spending of smokers in the target Asia-Pacific countries (Hong Kong, Malaysia, Thailand, South Korea, Singapore, and Australia) on purchasing cigarettes, as well as predicted the revenue that could be generated if smokers spent the money on investment instead of buying cigarettes. Smokers' spending on cigarettes and the potential revenue generated from investment were estimated based on the selling prices of cigarettes, Standards \& Poor's 500 Index, and life expectancies of smokers. Data were extracted from reports released by the World Health Organization or government authorities.

RESULTS The annual expenses (in US\$) on purchasing one pack of cigarettes, in decreasing order, were: Australia (\$5628.30), Singapore (\$3777.75), Hong Kong (\$2799.55), Malaysia (\$1529.35), South Korea (\$1467.30), and Thailand (\$657.00). The lifetime spending on purchasing one pack of cigarettes each day were: Australia (\$308993.67), Singapore (\$207398.48), Hong Kong (\$151735.61 for male and $\$ 166853.18$ for female), South Korea (\$80261.31), Malaysia (\$72338.26), and Thailand (\$31207.50).

CONCLUSIONS The cost burden of smoking is high from a smoker's perspective. Smokers should recognize the high economic burden and quit smoking to enjoy better health and wealth.

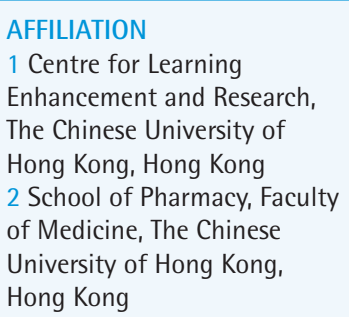

CORRESPONDENCE TO

Vivian W. Y. Lee. Centre for Learning Enhancement and Research, The Chinese University of Hong Kong, 502, Hui Yeung Shing Building, Shatin, N.T., Hong Kong. E-mail address: vivianlee@ cuhk.edu.hk

ORCID ID: https://orcid. org/0000-0001-5802-8899

\section{KEYWORDS}

smoking cessation, cigarette, Asia, healthcare expenditures, burden of smoking

Received: 13 October 2020 Revised: 17 February 2021

Accepted: 22 February 2021

\section{INTRODUCTION}

Smoking is a well-established modifiable risk factor for many chronic diseases, including cardiovascular diseases, cerebrovascular diseases, and respiratory diseases. Globally, over 8 million people are killed by tobacco each year. More than 7 million deaths are due to direct tobacco use while about 1.2 million deaths are due to secondhand smoke exposure ${ }^{1}$.

Asian countries are in the early stages of the tobacco smoking epidemic. The projected prevalence of consuming any tobacco product among males aged $\geq 15$ years in 2020 was: $40.2 \%$ in Malaysia, $39.7 \%$ in Thailand, $46.9 \%$ in South Korea, $28.3 \%$ in Singapore, $14.3 \%$ in Australia, and $10.0 \%$ in Hong Kong ${ }^{2}$. The
World Health Organization Framework Convention on Tobacco Control recommends that all Asian countries implement comprehensive tobacco control policies such as raising tobacco taxes and prices, and implementing smoke-free laws, to reduce smoking prevalence in $\mathrm{Asia}^{3}$. Tobacco is also the leading cause of cancer in Australia, which contributes to $22 \%$ of the cancer burden ${ }^{4}$. The Australian government has implemented a tobacco advertising ban, plain packaging law, law on smoking in public, and age limit in purchasing cigarettes, to reduce tobacco use.

Smoking would undoubtedly impose far-reaching consequences to human health. Traditionally, authorities tend to promote smoking cessation by 
emphasizing the undesirable impact of smoking on health. Nevertheless, the direct economic impact of smoking on smokers is not often discussed. While some studies have attempted to predict the healthcare burden imposed on society due to smoking ${ }^{5}$, relatively few studies have estimated the economic impact of smoking on individual smokers. This study investigated the financial impact of smoking on an individual level to determine the burden of smoking in six Asia-Pacific countries, namely, Hong Kong, Malaysia, Thailand, South Korea, Singapore, and Australia. We aimed to estimate smokers' spending on cigarettes and show smokers that giving up smoking can bring them better wealth.

\section{METHODS}

The current study estimated the annual spending and lifetime spending of smokers on purchasing cigarettes, as well as predicted the revenue that could be generated if smokers spent the money on investment instead of buying cigarettes.

We estimated the annual spending and lifetime spending of smokers on purchasing cigarettes if they smoked 1 pack, 1.5 packs, 2 packs or 3 packs of cigarettes each day starting from the age of 18 years. Inflation or changes in cigarette prices over time were not taken into account in the above estimations. The selling price of cigarettes in Hong Kong were cited from government reports ${ }^{6}$, while those of target Asia-Pacific countries were determined from data released by the World Health Organization (WHO $)^{7}$. Citizens' average life expectancies at birth were used to estimate their lifetime spending on cigarettes. Data for Hong Kong were from government reports, while those of the target Asia-Pacific countries were from data released by $\mathrm{WHO}^{8,9}$.

In addition, references were made to Standards \& Poor's 500 Index (S\&P 500) to estimate the revenue smokers could return on retirement if they used the money to make investments instead of buying cigarettes. S\&P 500, which was a widely reported stock market index that measured the stock performance of 500 companies in the United States, was chosen to avoid bias towards any country in this study.

Amount returned from investment in 2019 was calculated from:

Amount $=a\left(\frac{1-r^{n}}{1-r}\right)$ where $a$ is the annual expense, $r$ the annualized growth rate of the S\&P 500, and $n$ the period. The formula was used to predict the amount that could be generated when the smokers retired.

\section{RESULTS}

Table 1 shows the out-of-pocket amount smokers spent on purchasing cigarettes in Hong Kong, Malaysia, Thailand, South Korea, Singapore, and Australia. Prices listed in Table 1 refer to the retail price of one pack of the most-sold brand of cigarettes in each country in 2018, as reported by WHO. In general, cigarette smoking would reduce average life expectancy by about 10 years. Therefore, we deducted 10 years from average life expectancies at birth when calculating the lifetime expenses on cigarettes. Annual expenses and lifetime expenses (starting from the age of 18 years) were calculated as 365 days per year. Retail prices of one pack of cigarettes were $\$ 7.67$ in Hong Kong, \$4.19 in Malaysia, \$1.80 in Thailand, $\$ 4.02$ in South Korea, \$10.35 in Singapore, and $\$ 15.42$ in Australia. Annual expenses of purchasing one pack of cigarettes per day would be $\$ 2799.55$ in Hong Kong, \$1529.35 in Malaysia, \$657.00 in Thailand, \$1467.30 in South Korea, \$3777.75 in Singapore, and \$5628.30 in Australia.

Furthermore, we estimated the revenue smokers could gain if they invested the money spent on cigarettes. Assuming a person started investing at the age of 18 years and retired at the age of 60 years, it would be equivalent to an investment period of 42 years. The annualized growth rate of the S\&P 500 between January 1976 and December 2018 was $7.39 \%$, adjusted for inflation ${ }^{10}$. Table 1 shows the estimated amount that would be returned when a person retired if he invested the money of buying 1 pack, 1.5 packs, 2 packs, or 3 packs of cigarettes.

\section{DISCUSSION}

Among the six countries, the selling price of cigarettes was highest in Australia, Singapore, and Hong Kong. Annual expenses to purchase one pack of cigarettes each day were $\$ 5628.30$ in Australia, $\$ 3777.75$ in Singapore, and \$2799.55 in Hong Kong. This spending corresponds to a substantial portion of a citizen's income. It was reported that the all-employees average weekly total earnings in Australia was AUD 1238.30 (\$854.43) in May 
Table 1. Financial impact of cigarettes on individuals and society in target Asia-Pacific countries

\begin{tabular}{|c|c|c|c|c|c|c|c|c|c|c|c|c|}
\hline Impact & \multicolumn{4}{|c|}{ Hong Kong } & \multicolumn{4}{|c|}{ Malaysia } & \multicolumn{4}{|c|}{ Thailand } \\
\hline Cost per pack (US\$) ${ }^{6,7}$ & \multicolumn{4}{|c|}{7.67} & \multicolumn{4}{|c|}{4.19} & \multicolumn{4}{|c|}{1.80} \\
\hline $\begin{array}{l}\text { Average life expectancy } \\
\text { (years) } 8,9\end{array}$ & \multicolumn{4}{|c|}{$\begin{array}{c}\text { Male: } 82.2 \\
\text { (Female: } 87.6 \text { ) }\end{array}$} & \multicolumn{4}{|c|}{75.3} & \multicolumn{4}{|c|}{75.5} \\
\hline $\begin{array}{l}\text { Average life expectancy for } \\
\text { smokers (years) }\end{array}$ & \multicolumn{4}{|c|}{$\begin{array}{c}\text { Male: } 72.2 \\
\text { (Female: } 77.6 \text { ) }\end{array}$} & \multicolumn{4}{|c|}{65.3} & \multicolumn{4}{|c|}{65.5} \\
\hline Number of packs per day & 1 & 1.5 & 2 & 3 & 1 & 1.5 & 2 & 3 & 1 & 1.5 & 2 & 3 \\
\hline $\begin{array}{l}\text { Annual expenses for one } \\
\text { pack per day (US\$) }\end{array}$ & $\begin{array}{l}2799.55 \\
(2799.55)\end{array}$ & $\begin{array}{c}4199.33 \\
(4199.33)\end{array}$ & $\begin{array}{c}5599.10 \\
(5599.10)\end{array}$ & $\begin{array}{c}8398.65 \\
(8398.65)\end{array}$ & 1529.35 & 2294.03 & 3058.70 & 4588.05 & 657.00 & 985.50 & 1314.00 & 1971.00 \\
\hline $\begin{array}{l}\text { Lifetime expenses for one } \\
\text { pack per day (US\$) }\end{array}$ & $\begin{array}{c}151735.61 \\
(166853.18)\end{array}$ & $\begin{array}{c}227603.69 \\
(250280.07)\end{array}$ & $\begin{array}{c}303471.22 \\
(333706.36)\end{array}$ & $\begin{array}{c}455206.83 \\
(500559.54)\end{array}$ & 72338.26 & 108507.38 & 144676.51 & 217014.77 & 31207.50 & 46811.25 & 62415.00 & 93622.50 \\
\hline SCAP 500 CAGR & \multicolumn{4}{|c|}{$7.39 \%$} & \multicolumn{4}{|c|}{$7.39 \%$} & \multicolumn{4}{|c|}{$7.39 \%$} \\
\hline $\begin{array}{l}\text { Total amount at retirement } \\
\text { if invested in SCPP } 500 \text { index } \\
\text { (US\$) }\end{array}$ & 718819.55 & 1078230.61 & 1437639.10 & 2156458.66 & 392679.78 & 589019.67 & 785359.56 & 1178039.34 & 168692.98 & 253039.48 & 337385.97 & 506078.95 \\
\hline Countries & \multicolumn{4}{|c|}{ South Korea } & \multicolumn{4}{|c|}{ Singapore } & \multicolumn{4}{|c|}{ Australia } \\
\hline Cost per pack (US\$) ${ }^{7}$ & \multicolumn{4}{|c|}{4.02} & \multicolumn{4}{|c|}{10.35} & \multicolumn{4}{|c|}{15.42} \\
\hline $\begin{array}{l}\text { Average life expectancy } \\
\text { (years) }{ }^{9}\end{array}$ & \multicolumn{4}{|c|}{82.7} & \multicolumn{4}{|c|}{82.9} & \multicolumn{4}{|c|}{82.9} \\
\hline $\begin{array}{l}\text { Average life expectancy for } \\
\text { smokers (years) }\end{array}$ & \multicolumn{4}{|c|}{72.7} & \multicolumn{4}{|c|}{72.9} & \multicolumn{4}{|c|}{72.9} \\
\hline Number of packs per day & 1 & 1.5 & 2 & 3 & 1 & 1.5 & 2 & 3 & 1 & 1.5 & 2 & 3 \\
\hline $\begin{array}{l}\text { Annual expenses for one } \\
\text { pack per day (US\$) }\end{array}$ & 1467.30 & 2200.95 & 2934.60 & 4401.90 & 3777.75 & 5666.63 & 7555.50 & 11333.25 & 5628.30 & 8442.45 & 11256.60 & 16884.90 \\
\hline $\begin{array}{l}\text { Lifetime expenses for one } \\
\text { pack per day (US\$) }\end{array}$ & 80261.31 & 120391.97 & 160522.62 & 240783.93 & 207398.48 & 311097.71 & 414796.95 & 622195.43 & 308993.67 & 463490.51 & 617987.34 & 926981.01 \\
\hline SEP 500 CAGR & \multicolumn{4}{|c|}{$7.39 \%$} & \multicolumn{4}{|c|}{$7.39 \%$} & \multicolumn{4}{|c|}{$7.39 \%$} \\
\hline $\begin{array}{l}\text { Total amount at retirement } \\
\text { if invested in SAP } 500 \text { index } \\
\text { (US\$) }\end{array}$ & 376747.67 & 565121.50 & 753495.33 & 1130243.00 & 969984.66 & 1454976.99 & 1939969.33 & 2909953.99 & 1445136.57 & 2167704.85 & 2890273.14 & 4335409.71 \\
\hline
\end{tabular}


$2019^{11}$, the median monthly household income from work per household member in Singapore was SGD 2792 (\$2066.08) in $2018^{12}$, and the median monthly employment earnings of employed persons (excluding foreign domestic helpers) in Hong Kong was HKD 18900 ( $\$ 2457.00$ ) in the third quarter of $2019^{13}$. In other words, smokers were spending annually more than the money they earned in one month to smoke one pack of cigarettes each day.

The economic impact of smoking would be more obvious if smokers considered the potential profit generated from the investment. On average, each smoker in Hong Kong smokes 12.4 cigarettes per day, which is equivalent to an annual expense of $\$ 1735.72^{14}$. Investing this amount could generate $\$ 445667.87$, which is equivalent to 15.11 years of working, and it is close to the market price of a 533 square feet private housing apartment in Hong Kong. If smokers invest the cost of one pack of cigarettes per day in the stock market, an amount equivalent to 24.38 years of working could be generated and smokers could purchase an 820 square feet private apartment in Hong Kong. Smokers should recognize the financial impact of smoking and the benefit of smoking cessation.

The current study illustrates the direct expenses of smokers on cigarette smoking. Nonetheless, the economic burden of smoking to individual smokers is in fact much heavier if indirect expenditures such as healthcare costs for managing smoking-related diseases and productivity loss from taking smoking breaks and absenteeism are taken into consideration. Although smoking is a well-proven modifiable risk factor for multiple diseases, citizens may not fully recognize the health impacts of smoking. For example, it was reported that citizens were aware that smoking would increase the risk of lung cancer, but they were less aware of the increase in the risk of cardiovascular diseases or stroke ${ }^{15}$. It indicates that there are ramifications of smoking of which smokers are not fully aware. Smokers should be educated that smoking cessation can alleviate the economic burden on both individuals and society.

\section{CONCLUSIONS}

Smoking imposes a huge financial burden on smokers. Smokers should recognize the economic impact of smoking and reduce tobacco use to optimize the value of their money.

\section{REFERENCES}

1. World Health Organization. Tobacco. 2019. Accessed December 23, 2020. https://www.who.int/news-room/ fact-sheets/detail/tobacco

2. World Health Organization. Risk factors: Prevalence of current tobacco use among adults. 2015. Accessed October 13, 2020. https://apps.who.int/gho/data/view. main.GDO2102v

3. WHO Framework Convention on Tobacco Control. World Health Organization; 2003. Accessed October 13, 2020. https://apps.who.int/iris/bitstream/ handle/10665/42811/9241591013.pdf;jsessionid= 406AE5812052638390FDF311D6E29455? sequence $=1$

4. Australian Institute of Health and Welfare. Alcohol, tobacco and other drugs in Australia. Accessed October 13, 2020. https://www.aihw.gov.au/reports/alcohol/alcoholtobacco-other-drugs-australia/contents/introduction

5. GBD 2015 Tobacco Collaborators. Smoking prevalence and attributable disease burden in 195 countries and territories, 1990-2015: a systematic analysis from the Global Burden of Disease Study 2015. Lancet. 2017;389(10082):18851906. doi:10.1016/S0140-6736(17)30819-X

6. Heat up as prices for smokes see first rise in two years. The Standard. July 20, 2018. Accessed December 23, 2019. http://www.thestandard.com.hk/section-news. php?id=198092\&sid=4

7. World Health Organization. Tobacco taxes and prices. Table 9.1 Taxes and Retail Price of a Pack of 20 Cigarettes of the Most Sold Brand. Accessed October 13, 2020. https://www.who.int/tobacco/global_report/2017/ appendix-ix/en/

8. Hong Kong Department of Health. Health Facts of Hong Kong: 2019 Edition. 2019. Accessed October 13, 2020. https://www.dh.gov.hk/english/statistics/statistics_hs/ files/Health_Statistics_pamphlet_E.pdf

9. World Health Organization. Life Expectancy at Birth (years), 2000-2016: Both Sexes: 2016. 2018. Accessed October 13, 2020. http://gamapserver.who.int/gho/ interactive_charts/mbd/life_expectancy/atlas.html

10. Moneychimp. Compound Annual Growth Rate (Annualized Return). December 23, 2019. http://www. moneychimp.com/features/market_cagr.htm

11. Australian Bureau of Statistics. 6302.0 - Average Weekly Earnings, Australia, May 2019. Accessed October 13, 2020. https://www.abs.gov.au/ausstats/ abs@.nsf/7d12b0f6763c78caca257061001cc588/ c4fc8fdc39fec7d9ca25845600162519!OpenDocument

12. Singapore Department of Statistics. Key Household Income Trends, 2018. 2018. Accessed October 13, 2020. https://www.singstat.gov.sg/-/media/files/publications/ households/pp-s25.pdf

13. The Government of the Hong Kong Special Administrative Region - Census and Statistics Department. Quarterly Report on General Household Survey (Third Quarter 2019). 2019. Accessed October 13, 2020. https://www. 
statistics.gov.hk/pub/B10500012019QQ03B0100.pdf

14. The Government of the Hong Kong Special Administrative Region - Census and Statistics Department. Pattern of Smoking. Hong Kong Monthly Digest of Statistics. January 2019. Accessed October 13, 2020. https://www. statistics.gov.hk/pub/B71901FB2019XXXXB0100.pdf

15. Eriksen M, Mackay J, Schluger N, Islami FG, Drope J. The Tobacco Atlas. 5th ed. American Cancer Society; 2015. Accessed October 13, 2020. https://ncdalliance.org/sites/ default/files/resource_files/TA5_2015_WEB.pdf

\section{ACKNOWLEDGEMENTS}

We thank Rex S.K. Leung for his contributions on the study design of this report.

\section{CONFLICTS OF INTEREST}

The authors have completed and submitted the ICMJE Form for Disclosure of Potential Conflicts of Interest and none was reported.

FUNDING

There was no source of funding for this research.

PROVENANCE AND PEER REVIEW

Not commissioned; externally peer reviewed. 